\title{
Study on Evaluation of Economical and Intensive Use of Construction Land in Shahe City
}

\author{
Hongjie $\mathrm{Liu}^{1 *}, \mathrm{Yu} \mathrm{Su}^{1}$ and Jing $\mathrm{Ma}^{1}$ \\ ${ }^{1}$ Urban Construction School, Beijing City University, Beijing, 101399, China
}

\begin{abstract}
Taking Shahe City of Hebei Province as an example, a reasonable evaluation index system of population, economy and land was established, and construction land economical and intensive utilization level of Shahe City was evaluated using analytic hierarchy process. The results showed that the economical and intensive utilization of construction land in Shahe City was in the middle level, and the value was 74.43. The result of the evaluation roughly reflected the economical and intensive utilization of construction land in Shahe City. The corresponding policy suggestions and measures aiming at the problem of land use status were put forward
\end{abstract}

\section{Introduction}

The rational and efficient use of land resources is an important condition for sustainable urban development. It is a long-term basic policy of China to adhere to the principle of economical and intensive land use [1]. However, with the continuous development of society and economy, the process of urbanization continues to advance, the scale of construction land is gradually expanding, the conflict between land supply and demand is increasingly intensified, and the problems of extensive and inefficient use of construction land continue to exist and have an intensifying trend. Under the situation and pressure, intensive use of urban land is considered as an effective way to alleviate the contradiction between supply and demand of construction land and solve the inefficient use of construction land [2]. At present, scholars have studied the evaluation of intensive use of construction land in different perspectives, methods and spatial scales [3-9].

\section{Basic data and research method}

\subsection{Overview of the study area}

Shahe City is located in the southwestern part of Hebei Province, at the eastern foot of the southern section of Taihang Mountain, between Handan City and Xingtai City, west to Wuan City, east to Nanhe County, south to Yongnian County, and north to Xingtai City and Xingtai County. It is adjacent to the east longitude $113^{\circ} 52^{\prime}$ $113^{\circ} 40^{\prime}$ and the latitude $36^{\circ} 49^{\prime}-37^{\circ} 07^{\prime}$. The widest part of the jurisdiction is $21.5 \mathrm{~km}$ from the north to the south, and the longest part from east to west is $87.5 \mathrm{~km}$. The area is $95817.16 \mathrm{ha}$, and the three national transportation arteries of the Beijing-Guangzhou Railway, Beijing-
Hong Kong-Macao Expressway, and 107 National Highway pass through the territory. The city has five streets, five towns, five townships, and 282 administrative villages. By the end of 2017, the city's population reached 422,600 .

The characteristics of land use in Shahe City are as follows: First, the characteristics of the layout of regional land use are obvious. The overall distribution trend of land resource types in Shahe City: the eastern urban area and central towns are more developed in industry and commerce. The proportion of urban and rural construction land is large, and the proportion of cultivated land in the plain area is large; the proportion of garden land, forest land and other land in the western hilly area is large. Second, the use of rural residential land is extensive. The scale of urban and rural construction land reached $15,420.12$ ha in 2017, of which the rural residential area was 9060.6 ha, accounting for $58.76 \%$ of urban and rural construction land; per capita construction land in rural areas is 235.96 $\mathrm{m} 2$, exceeding the maximum standard of $150 \mathrm{~m} 2$ per person in the "Village Planning Standards"(GB501882007 (93)). Third, there is great potential for the development of reserve resources. The area of other land in Shahe City is 26205.62 ha, accounting for $27.35 \%$ of the total land area. The scale of reserve resources that can be comprehensively renovated is 26104.49 ha, accounting for $99.61 \%$ of other land areas.

\subsection{Research data sources}

The data to be collected include basic data and related data, and basic data includes population, economic and land use data. Household registration data and resident population data are directly used in the statistical summary data, and economic data are used in Xingtai

"Corresponding author: 1_hongiie@163.com 
statistical summary data of 2018, of which the total regional production is obtained using the gross national product of 2018. The land data is based on the land use change survey data from 2014 to 2018 and the 3rd land survey data provided by the Shahe Land and Resources Bureau.

\subsection{Research method}

\subsubsection{Establishment of evaluation index system}

The evaluation of construction land use adopts a multifactor comprehensive evaluation method. By selecting an evaluation index system, standardization of the ideal values of the indicators, the overall intensive use of construction land in Shahe City is calculated by the subindex, index and total index, reflecting the overall level,

regional differences and dynamic trends of the intensive use of construction land in Shahe City.

The index system includes 4 indexes such as land use intensity, 7 sub-indexes such as population density, and 11 indicators such as population density of urban and rural construction land. The weight values should be based on the effect of indexes, sub-indexes, and indicators to regional economic and intensive use of construction land. The weight values of each index, subindex, and indicators should be between 0 and 1, the sum of the weight values of each index, each sub-index under the same index, and the indicators of the same sub-index is 1. The evaluation is based on the national unified weight value and is modified by Delphi method. The evaluation index system and weight are detailed in table 1 .

Table 1. Evaluation index system and weight

\begin{tabular}{|c|c|c|c|c|c|}
\hline Index & weight & Sub-index & weight & indicator & weight \\
\hline \multirow{2}{*}{$\begin{array}{c}\text { Use } \\
\text { Intensity } \\
\text { Index } \\
\text { (UII) }\end{array}$} & 0.5 & $\begin{array}{l}\text { Population } \\
\text { Density Index } \\
\quad \text { (PUII) }\end{array}$ & 0.38 & $\begin{array}{l}\text { Urban and rural construction land population density } \\
\text { (PUII1) }\end{array}$ & 1 \\
\hline & & $\begin{array}{l}\text { Economic } \\
\text { Intensity Index }\end{array}$ & 0.62 & Construction land investment in fixed assets (EUII1) & 0.46 \\
\hline \multirow[t]{2}{*}{$\begin{array}{c}\text { Growth } \\
\text { Land } \\
\text { Consumpti } \\
\text { on Index } \\
\text { (GCI) }\end{array}$} & 0.19 & $\begin{array}{l}\text { Population } \\
\text { Growth Land } \\
\text { Consumption } \\
\text { Index } \\
\text { (PGCI) }\end{array}$ & 0.37 & $\begin{array}{l}\text { Consumption of new urban and rural construction } \\
\text { land per unit population growth (PGCI1) }\end{array}$ & 1 \\
\hline & & & & $\begin{array}{l}\text { New construction land consumption per unit fixed } \\
\text { asset investment (EGCI3) }\end{array}$ & 0.3 \\
\hline \multirow[t]{2}{*}{$\begin{array}{l}\text { Elastic } \\
\text { Index of } \\
\text { Land Use } \\
\quad(\text { EI) }\end{array}$} & 0.16 & $\begin{array}{l}\text { Elastic Index of } \\
\text { Population } \\
\text { Land Use } \\
\text { (PEI) }\end{array}$ & 0.39 & $\begin{array}{l}\text { Elasticity coefficient of Population and urban and } \\
\text { rural construction land growth (PEI1) }\end{array}$ & 1 \\
\hline & & $\begin{array}{l}\text { Elastic Index of } \\
\text { Economy Land } \\
\text { Use (EEI) }\end{array}$ & 0.61 & $\begin{array}{l}\text { Regional GDP and Construction Land Growth } \\
\text { Coefficient (EEI1) }\end{array}$ & 1 \\
\hline
\end{tabular}

\subsubsection{Standardization of evaluation index.}

(1) Index standardization method. The standardization of the evaluation index should use the ideal value proportional inference algorithm. The initial value of the standardization of the index is calculated using formula (1):

$$
S_{i 0}=\frac{a_{i}}{t_{i}}
$$

Where $S_{i 0}$ is the initial value of the standardized value of the $\mathrm{i}$-th index; $t_{i}$ is ideal value of index $i ; a_{i}$ is the actual value of the $i$-th index.

(2) Sub-Index calculation. The sub-indexes for the evaluation of regional construction land use are calculated according to formula (2):

$$
\alpha_{j}=\sum_{i=1}^{n}\left(w_{j i} \times S_{j i}\right) \times 100
$$


Where $\alpha_{j}$ is the value of the $\mathrm{j}$-th sub-index; $W_{j \mathrm{i}}$ is the weight of the $\mathrm{i}$-th index under the $\mathrm{j}$-th sub-index; $S_{j i}$ is the number of indicators under the j-th sub-index.

(3) Index calculation. The indexes for the evaluation of regional construction land use conditions are calculated according to formula (3):

$$
\beta_{\mathrm{k}}=\sum_{\mathrm{j}=1}^{\mathrm{n}}\left(\mathrm{w}_{\mathrm{kj}} \times \alpha_{\mathrm{j}}\right)
$$

Where $\beta_{k}$ is the value of the k-th index; $W_{k j}$ is the weight of the $\mathrm{j}$-th sub-index under the k-th index; $\alpha_{j}$ is the value of the $\mathrm{j}$-th sub-index.

(4)Total index calculation. The total index for the evaluation of regional construction land use is calculated according to formula (4):

$$
\text { total inde } x=\sum_{k=1}^{n}\left(\mathrm{w}_{\mathrm{k}} \times \beta_{\mathrm{k}}\right)
$$

Where $W_{k}$ is the weight of the k-th index; $\beta_{k}$ is the value of the k-th index; $n$ is the number of indices under the overall index.

\section{Results of evaluation of intensive use of construction land in Shahe City}

Based on the data obtained from the survey and the corresponding unified standards requirements, the current indicators of the overall evaluation of Shahe City were measured. The comparison of the calculated values with the ideal values was used to standardize the evaluation indicators, and then the evaluation of intensive use of construction land in Shahe City was calculated (table 2).

The overall evaluation index of intensive use of construction land in Shahe City is 74.43 , which means that the intensive use of construction land in Shahe City is at a medium level.

According to the evaluation results of regional construction land, the overall status, characteristics, problems, major gaps and reasons of intensive use of construction land in Shahe City are summarized, to clarify the improvement direction of intensive land use.

\subsection{Analysis of the current level of intensive use of construction land}

According to the calculation results of the overall use intensity index (UII) and the sub-indexes of Shahe City, combined with the current and ideal values of key indicators such as urban and rural construction land population density and the average gross domestic product of construction land, it can be concluded that the per capita land use intensity is medium, the urban population density is relatively large, and there is still a certain distance from the ideal value. The urban area is small, the fixed asset investment is growing rapidly, the per capita GDP is low, and rural construction land needs to be improved. It is necessary to rectify the phenomenon of hollow villages, withdraw and extensively develop villages, further accelerate the process of urbanization, further increase the intensity of investment in fixed assets, and increase the output of unit construction land.

\subsection{Analysis on the dynamic change trend of economical and intensive use of construction land}

According to the overall growth land consumption index (GCI), land use elasticity index (EI) and its sub-index calculation results in Shahe City, combined with key indicators such as the decline rate of land consumption per unit of GDP, the elasticity coefficient of population and urban and rural construction land growth, and other key indicators, compared with the ideal value, the current land consumption rate of Shahe City is low, and the land consumption rate of unit GDP has decreased, but it is still far from the target. The unit GDP and the intensity of unit fixed assets investment in land consumption is large. It is necessary to increase the intensity of investment in fixed assets, increase the income of land resources, increase the use of economic leverage to control and rationally allocate construction land resources.

\subsection{Analysis and Evaluation of the Overall Situation of Economical and Intensive Use of Construction Land}

According to the total index of economical and intensive use of construction land, we can conclude that the land use intensity of Shahe City is medium, but the growth land consumption index and elasticity index are low. The main reasons for the above are: (1) Urbanization development is slow, and the rural population increases with the scale of village land, but the lack of rational planning of village land causes the rapid growth of village construction land, which does not match the rural population growth; (2) Shahe City is an industrial city, Although the tertiary industry has made considerable progress in recent years, the proportion is still small, and the secondary industry still occupies a large proportion. Compared with the tertiary industry, the fixed asset investment scale and national land production per unit of the secondary industry is relatively low. (3) Enterprises lack the concept of land conservation, and the landsaving technology is backward, resulting in waste of land resources. 
Table 2. The results of the evaluation index of construction land in Shahe City

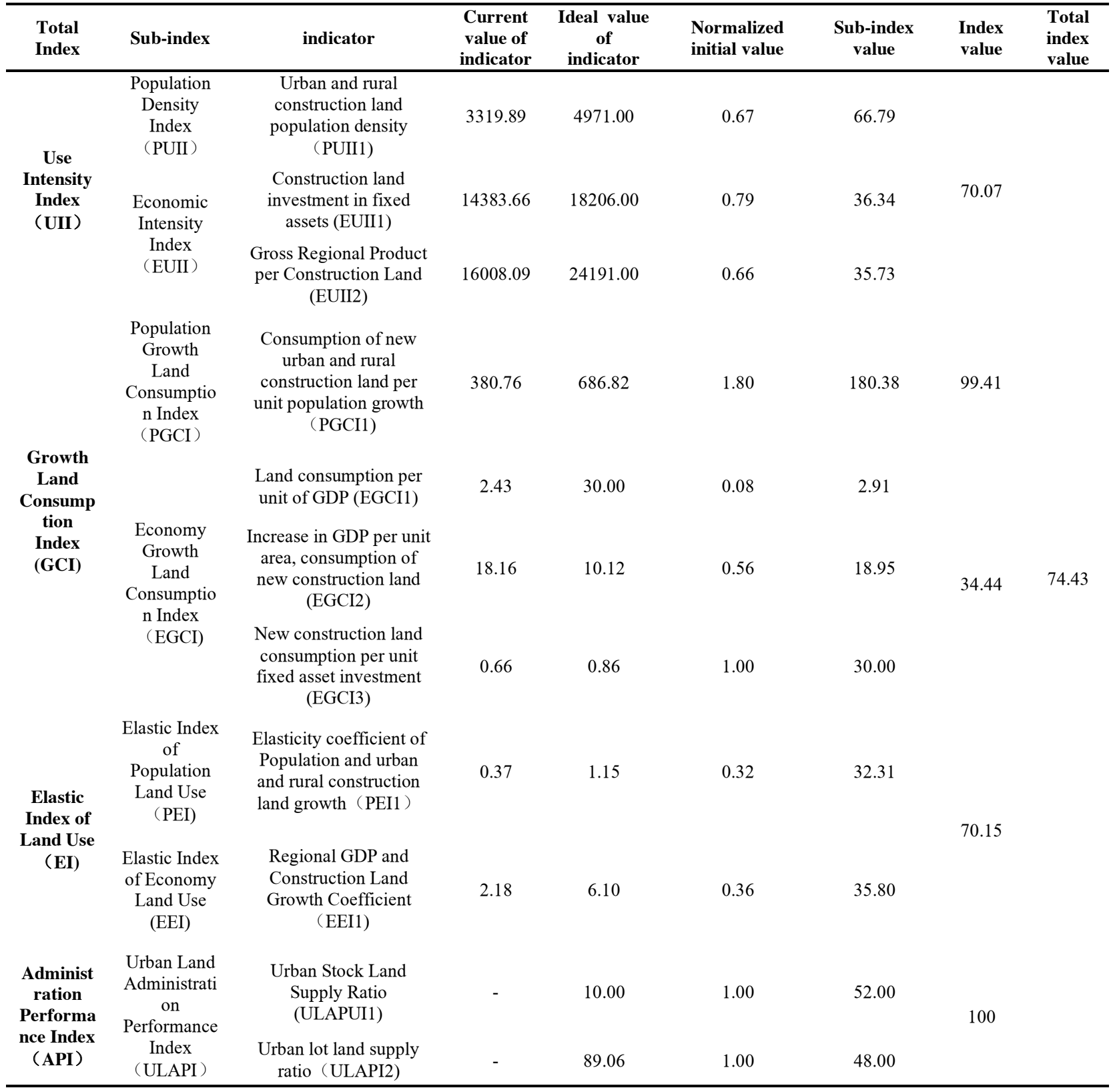

\section{Suggestions on measures for} economical and intensive use of construction land in Shahe City

\subsection{Adhere to overall and rational planning for land}

In the process of making land plans, it is necessary to effectively contact the urban planning, regional development planning, and national economic planning, and always adhere to the guidelines for economical and intensive land use, to prevent the phenomenon of blind expansion during this stage, and to achieve economical and intensive land use through reasonable planning. Comprehensive management methods should be used to effectively control the overall planning and thus effectively improve the scientific and rational use of land resources, to achieve economical and intensive use of land resource.

\subsection{Control the growth rate of urban and rural construction land and improve comprehensive benefits of land}

In the critical stage of economic development, although the rapid growth of urban and rural construction land has its reasonable side, the sustainable development of population, resources, and the environment must be maintained. Policy-driven levers should be used to give certain support to areas with weak land-carrying populations, and certain regional key cities and towns can be cultivated with the help of tourism, industry and other industries, to realize urbanization of population, 
reducing the pendulum movement of the population and the phenomenon of "dual land occupation". Taking the link between urban and rural construction land increase and decrease, comprehensive improvement of rural land, and industrial and mining wasteland reclamation and utilization as the starting points, the improvement and reuse of rural construction land should be vigorously implemented. At the same time, we will strengthen the management of the approval of new rural land, strictly investigate and deal with illegal acts such as arbitrarily changing the use of contracted land to build houses, and effectively solve the problem of decreasing rural population and increasing village land, and gradually realize that rural land will decrease as the rural permanent population decreases.

\subsection{Increase the vitality of stock land}

Under the premise of controlling the total scale of construction land, in order to meet the demand of land for economic and social development, we must focus on releasing the space for the stock of construction land. Taking the opportunity of the pilot redevelopment of low-efficiency urban land as an opportunity, we should tap the potential of the stock of construction land. We must pay attention to old urban areas, reconstruction of old residential areas and old factories, gaining an increase from the stock, seeking development space at the level of efficiency, effectively promoting the transformation and upgrading of traditional industries, and eliminating backward production capacity; effectively dealing with idle land, using mergers, acquisitions and transfer of land and other means, to obtain land use rights, but also to increase the intensity of development and construction, if necessary, the government can take measures to recover the idle land; we should find land resources at the spatial level and promote the development of three-dimensional land, making "above" and the "underground" space can be fully used, so that the unit land plot ratio is greatly strengthened.

\subsection{Strengthen dynamic monitoring of intensive land use}

We should continuously optimize the land law enforcement supervision system, truly implement law enforcement supervision, use advanced technical measures and monitoring equipment to effectively control land resources in the area under jurisdiction, implement a land law enforcement dynamic inspection responsibility mechanism, and greatly optimize the contact coordination system. The development and utilization of land can have a legal basis to expose the disadvantages of land conservation and intensive use, and continue to optimize and adjust land use methods, and strengthen the monitoring of the current status of land use. If the phenomenon of land abandonment or unauthorized change of use occurs, then it must be severely punished. In addition, it is necessary to effectively strengthen the monitoring of public opinion, truly listen to the reports of the general public, and effectively promote the implementation of land law enforcement and supervision tasks.

\section{References}

1. Ren F, Wei S.Study on the evaluation of economical and intensive use of regional construction landtaking sanya city as an example [J]. Shanghai Land and Resources, 37 (3): 35-39, 70 (2016)

2. Zhao X, Huang X, Chen Y, et al. Research progress on intensive use of urban land [J]. Journal of Natural Resources, 25 (11): 1979-1996 (2010)

3. Wang $\mathrm{H}, \mathrm{Yu} \mathrm{X}$, Zhou B, etc. Evaluation on the economical and intensive land use of Jiangbei District, Chongqing City, Natural Resource Economics of China, 12:48-52(2015)

4. Liu Q, Ma Y Evaluation and Suggestions on Economical and Intensive Use of Construction Land-A Case Study of Xiangxiang County, Land \& Resources Herald, 14(2): 91-96 (2017)

5. Guan T, Jiang M, Ouyang A, etc. Analysis on the dynamic change characteristics and the general trend of economical and intensive use of urban construction land in Zhejiang, Shanghai Land \& Resources, 38(1):4-8(2017)

6. Bi M, Zhou Y. Study on evaluation of intensive and intensive use of construction land in Guyuan City [j]. Land Development Engineering Research, 2 (11): 15 (2017)

7. Zhang Y, Yan H, Pan F Discussion on the Method of Determining the Ideal Value of Economical and Intensive Use Assessment of Regional Construction Land-A Case of Shandong Province, Journal of Anhui Agricultural Sciences, 46(6):216-218 (2018)

8. Xing L, Li S, Liu Y, et al. Comparative study on evaluation of economical and intensive use of construction land in urban areas_-Taking Fuyu City, Dunhua City, Jiutai District of Jilin Province as examples [J]. Hubei Agricultural Sciences, 57 (7): 32-35, 40 (2018)

9. Yu S. Study on the evaluation of economical and intensive use of regional construction landTaking Fuxin City, Liaoning Province as an example [J]. Resources \& Land, 5: 44-47 (2019) 